\title{
How gender matters for happiness: A serial study in of college students in China
}

Xiao Dong Yue ${ }^{*}$, Feng Jiang, Hiranandani Neelam Arjan, Huang Jia and Li Su-Xia

Department of Applied Social Studies, City University of Hong Kong, 81 Chee Avenue, Kowloon Tong, Hong Kong SAR China

\begin{abstract}
Studies in the past have found that gender plays an important role in happiness. This study examines gender difference in happiness and depression in Chinese society, with regard to the Five Factor Model (FFM). Totally, 5648 students (aged between 17 and 29) were recruited from universities in China. Results indicated that women reported higher happiness and higher depression than men. The present study provides empirical data that women tend to express more emotional feelings, like gratitude and happiness. Moreover, results showed that extraversion mediated women' experience of subjective happiness and depression whereas neuroticism mediated women' experience of depression. The results of the present study reconfirmed that extraversion was the most reliable predictor of positive affect (e.g., happiness) while neuroticism was the most reliable predictor of negative affect (e.g., depression).
\end{abstract}

\section{Introduction}

Happiness is defined as a prevalence of positive over negative affect and a satisfaction with life as a whole [1,2]. The adaptation-level theory suggests that people judge the pleasantness or unpleasantness of events or circumstances based on the positive and negative experiences of the individual [3]. According to this perspective, habituation makes extreme circumstances appear more normal to the individual, hence, in other words, happiness is subjective as individuals' happiness and unhappiness could depend on how one judge the pleasantness of events or circumstances.

Gender roles and attitudes have shown to play an important role to signify gender-specific responsibilities and beliefs [4], which goes further than playing a role and carrying out duties [5]. Stereotypical portrayals of men and women roles persists till today [4], for instance, traditionally, men usually are the bread-winners, while, women typically enact the caretaker roles' at home as a mother and a wife [6]. Therefore, women are usually sensitive to the needs of others and emotional expression [6], and they also have a tendency to report more extreme positive and negative feelings. There have been marked changes in gender role attitudes and responsibilities. For instance, men and women are increasingly open to women pursuing education and career goals and men helping with the housework [4]. With the increasing changes in gender attitudes and gender roles, young men and women are expected to work outside the house, and to expect women to work more for family and household chores $[4,7,8]$.

\section{Happiness and Gender}

Previous studies also reveal that gender was related to subjective well-being that women tended to report higher happiness than men [6,9-12]. For example, in a sample of 600 Taiwan Chinese people, women scored significantly higher than men on happiness measures (Women: $M=70.65$, Men: $M=66.95 ; t=1.97, p<0.05$ ) as well as with greater variance (Levene's $\mathrm{p}<.001$ ) [13]. Similar findings were also reported in studies of subjective well-being [14-18], suggesting that it is a cross-cultural property [19]. Besides, women tended to score higher than men on measures of neuroticism and depression [20]. For example, women were found to experience distress 30 percent more often than men and women tended to express negative emotions more often and more freely than men [21]. Women also tended to experience more depression even though they were just as happy as men [22].

\section{Happiness and the Big Five}

In addition to gender roles and socialization, recent studies have also showed that dispositional factors, such as gratitude and optimism could play a vital role in keeping high subjective well-being (SWB) and low depression [23-26]. Abundant studies have been conducted in the past to explore the relationship between the big five and happiness [27-30]. For example, in a study of 423 Chinese university students, extraversion and neuroticism were found to predict happiness significantly [30]. In addition, extraversion was significantly and positively correlated with leisure satisfaction, and the opposite was true for neuroticism. In another study of 235 American university students, extraversion was found to predict happiness whereas neuroticism was found to predict unhappiness [31]. Extraversion was also found to be positively correlated with positive affect and to be negatively correlated with negative affect [31]. Moreover, extraversion and neuroticism predicted happiness and depression mediating through self-esteem [31].

Eysenck once remarked [32]; "Happiness is a thing called stable extraversion" (p. 87). Chamorro-Premuzic, Bennett and Furnham [33] argued that personality traits were "the most robust predictors of happiness". They reported that happiness was positively correlated with extraversion, agreeableness and conscientiousness. These personality traits (e.g., extraversion, agreeableness and conscientiousness) explained a considerable amount of variance in happiness [33]. DeNeve and Cooper [34] concluded that extraversion and agreeableness were the two most reliable predictors of positive affect while neuroticism was the most reliable predictor of negative affect and life dissatisfaction. Cheung and his colleagues [20] also reported that neuroticism and depression are closely related. Therefore, this study aims to investigate the interplay of the big five among subjective happiness and depression.

"Corresponding Author: Dr. Xiao Dong Yue, Department of Applied Social Studies, City University of Hong Kong, 81 Chee Avenue, Kowloon Tong, Hong Kong SAR China; E-mail: xiaodong.yue@cityu.edu.hk

Citation: Yue XD, Jiang F, Arjan HN, Jia H, Su-Xia L (2017) How gender matters for happiness: A serial study in of college students in China. Int J Psychol Behav Anal 3: 122. doi: https://doi.org/10.15344/2455-3867/2017/122

Copyright: () 2017 Yue et al. This is an open-access article distributed under the terms of the Creative Commons Attribution License, which permits unrestricted use, distribution, and reproduction in any medium, provided the original author and source are credited. 
Citation: Yue XD, Jiang F, Arjan HN, Jia H, Su-Xia L (2017) How gender matters for happiness: A serial study in of college students in China. Int J Psychol Behav Anal 3: 122. doi: https://doi.org/10.15344/2455-3867/2017/122

Page 2 of 6

\section{Aims of This Study and Hypotheses}

This study aims to investigate how gender affects happiness and depression among Chinese people. Based on previous studies, we propose two general hypotheses for this study, i.e., women tended to report higher happiness and higher depression than men (H1); extraversion would mediate women' experience of subjective happiness and depression whereas, neuroticism would mediate women' experience of depression (H2).

\section{Method}

\section{Participants}

Five thousand, six hundred and forty-eight students between the ages of 17 and 29 (2180 men and 3198 women and 193 unspecified gender) were recruited from universities in China. All the students were university students.

\section{Measures}

Subjective Happiness Scale: Subjective happiness scale consists of 4 items (e.g., "In general, I consider myself..., "Compared with my peers, I consider myself...") [35]. A total of 4 items were rated on a 7-point Likert scale, where 1 and 7 represents "not a very happy person, less happy, not at all" and "very happy person, more happy, a great deal", respectively $(\alpha=.74)$.

Self-Rating Depression Scale: The Self-Rating Depression Scale [36] consisted of 20 items (e.g., "I feel down-hearted and blue", "Morning is when I feel the best") on a 4-point scale where 1 represents "occasionally" and 4 represents "always" ( $\alpha=.75)$.

The Five Factor Model: The ten-item Personality inventory (TIPI) [37] consisted of 10 items to measure the Five Factor Model personality domains. Participants were required to rate on the self-report of how they viewed themselves on a 7-point scale where 1 represents disagree strongly and 7 represents agree strongly on all 10 items (e.g., "Extraverted, enthusiastic", "Critical, quarrelsome").

\section{Procedures}

Data were collected through questionnaires via a convenience sampling and were completed on a voluntary basis. The students completed these questionnaires in their free time. The questionnaires took approximately 15 to 20 minutes to complete.

\section{Results}

\section{Gender difference on depression and happiness}

Results indicate that women score significantly higher than men on subjective happiness $(M=20.47, S D=4.39)$ and depression $(M=$ $41.63, S D=8.14$ ) ( Table 1 ). This supports hypothesis 1 of this study that women would report higher happiness and higher depression than men.

Results indicated that women scored significantly higher than men across the Five Factor Model (FFM), including, openness $(t=2.83$, $p<.01)$, conscientiousness $(t=-2.65, p<.01)$, extraversion $(t=-3.57$, $p<.001)$, agreeableness $(t=-10.32, p<.001)$, and neuroticism ( $t=-3.97$, $p<.001$ ) (Table 2).

Subjective happiness was significantly and positively correlated with openness $(r=.25, p<.001)$, conscientiousness $(r=.20, p<.001)$, extraversion $(r=.35, p<.001)$, and agreeableness $(r=.25, p<.001)$ (Table 3$)$. Subjective happiness was also negatively correlated with neuroticism $(r=-.20, p<.001)$. Besides, depression was significantly and negatively correlated with openness $(r=-.21, p<.001)$, conscientiousness $(r=-.21, p<.001)$, extraversion $(r=-.10, p<.001)$, and agreeableness $(r=-.10, p<.001)$. Depression was negatively and positively correlated with neuroticism $(r=.20, p<.001)$. Generally, subjective happiness was negatively correlated with depression $(r=$ $-.34, p<.001)$.

We then conducted multiple meditational analyses using the 5,000 bootstrap samples and a bias corrected confidence interval to examine

\begin{tabular}{|l|l|l|l|l|l|l|}
\hline & Men $(N=2036)$ & Women $(N=2923)$ & & & & \\
\hline & M & SD & M & SD & t-value & Cohen's $d$ \\
\hline Subjective Happiness & 19.16 & 4.54 & 20.47 & 4.39 & $-10.16^{* * *}$ & -.29 \\
\hline & Men $(N=1944)$ & Women $(N=2626)$ & & & & \\
\hline & M & SD & M & SD & t-value & Cohen's $d$ \\
\hline Depression & 40.90 & 8.15 & 41.63 & 8.14 & $-2.97^{* * *}$ & -.09 \\
\hline
\end{tabular}

Table 1: Gender difference in happiness and depression.

Note: ${ }^{*} \mathrm{p}<.05,{ }^{* *} \mathrm{p}<.01,{ }^{* * *} \mathrm{p}<.001$

\begin{tabular}{|c|c|c|c|c|c|}
\hline & & M & SD & t-test & Cohen's d \\
\hline \multicolumn{6}{|l|}{ The Big-Five } \\
\hline Openness & Men & 9.91 & 2.25 & $2.83^{\star *}$ & .08 \\
\hline \multirow[t]{2}{*}{ Conscientiousness } & Men & 9.34 & 2.49 & $-2.65^{\star \star}$ & -.07 \\
\hline & Women & 9.52 & 2.45 & & \\
\hline Extraversion & Women & 8.63 & 2.75 & & \\
\hline \multirow[t]{2}{*}{ Agreeableness } & Men & 9.49 & 2.04 & $-10.32^{* * *}$ & -.29 \\
\hline & Women & 10.08 & 2.03 & & \\
\hline \multirow[t]{2}{*}{ Neuroticism } & Men & 7.47 & 2.35 & $-3.97^{* * *}$ & -.11 \\
\hline & Women & 7.74 & 2.41 & & \\
\hline
\end{tabular}

Table 2: Mean differences of the Five Factor Model by gender.

Note: ${ }^{\star} \mathrm{p}<.05,{ }^{* *} \mathrm{p}<.01,{ }^{* *} \mathrm{p}<.001$ 
Citation: Yue XD, Jiang F, Arjan HN, Jia H, Su-Xia L (2017) How gender matters for happiness: A serial study in of college students in China. Int J Psychol Behav Anal 3: 122. doi: https://doi.org/10.15344/2455-3867/2017/122

Page 3 of 6

\begin{tabular}{|c|c|c|c|c|c|c|c|}
\hline & 1 & 2 & 3 & 4 & 5 & 6 & 7 \\
\hline 1. Openness & 1 & - & - & - & - & - & - \\
\hline 2. Conscientiousness & $.29^{* * *}$ & 1 & - & - & - & - & - \\
\hline 3. Extraversion & $.27^{\star * *}$ & $.06^{* * *}$ & 1 & - & - & - & - \\
\hline 4. Agreeableness & .02 & $.15^{\star * *}$ & $.27^{* * *}$ & 1 & - & - & - \\
\hline 5. Neuroticism & $-.05^{\star * *}$ & $-.22^{* * *}$ & $.11^{* * *}$ & $-.22^{\star * *}$ & 1 & - & - \\
\hline 6. Subjective happiness & $.25^{\star * *}$ & $.20^{* * *}$ & $.35^{* * *}$ & $.09^{* * *}$ & $-.20^{\star * *}$ & 1 & - \\
\hline 7. Depression & $-.21^{\star * *}$ & $-.21^{\star * *}$ & $-.10^{* * *}$ & $-.10^{* * *}$ & $.20^{\star * *}$ & $-.34^{\star *}$ & 1 \\
\hline
\end{tabular}

Table 3: Correlations between Subjective happiness, Depression and the Five Factor Model.

Note: ${ }^{*} \mathrm{p}<.05,{ }^{* *} \mathrm{p}<.01,{ }^{* * *} \mathrm{p}<.001$

mediation effect of personality [38]. The mediator is significant when the $95 \%$ confidence intervals (CI) do not contain zero. For subjective happiness, as shown in Figure 1, extraversion significantly mediated the relationship between gender and subjective happiness $(95 \% \mathrm{CI}$ $=.03 .10)$. Also, neuroticism significantly mediated the relationship between gender and subjective happiness $(95 \% \mathrm{CI}=-.06-.02)$. For depression, neuroticism significantly mediated the relationship between gender and depression $(95 \% \mathrm{CI}=.03 .10)$. Therefore, the results partly support hypothesis 2 that extraversion mediated women' experience of subjective happiness and depression whereas neuroticism mediated women' experience of depression.

\section{Discussion}

Resultsindicated that women werefound toreportsignificantlyhigher happiness and depression than men. These results echoed previous findings that women tended to report higher happiness $[11,12]$ as well as higher depression [39-41] whereas men tended to report higher loneliness and lower emotional expressiveness [39-42]. This could be due to that men tended to express emotion associated with power and status such that their masculinity and social status would not be threatened [42-44]. Women, on the other hand, tended to express more emotional feelings, like gratitude and happiness $[45,46]$. This could be attributed to the gender role ideology that women tend to be sensitive to the needs of others and express their emotions more openly $[4,6]$ and women also have a tendency to report more extreme positive and negative feelings.

Furthermore, the Chinese perspective conceptualizes happiness with "being content with one's lot and feeling sincerely thankful for whatever life brings" [47]. This could indicate that women may have a tendency to be content with whatever life brings to them more easily than men. Happiness is conceived differently in every society of which different cultural values determine different understandings of happiness [47-49]. In Chinese society, for example, the Chinese characters of Fu-qi or Fu refer to happiness, which includes material abundance, physical health, a virtuous and peaceful life [49]. The Daoist Yin-Yang theory promotes a state of homeostasis such that

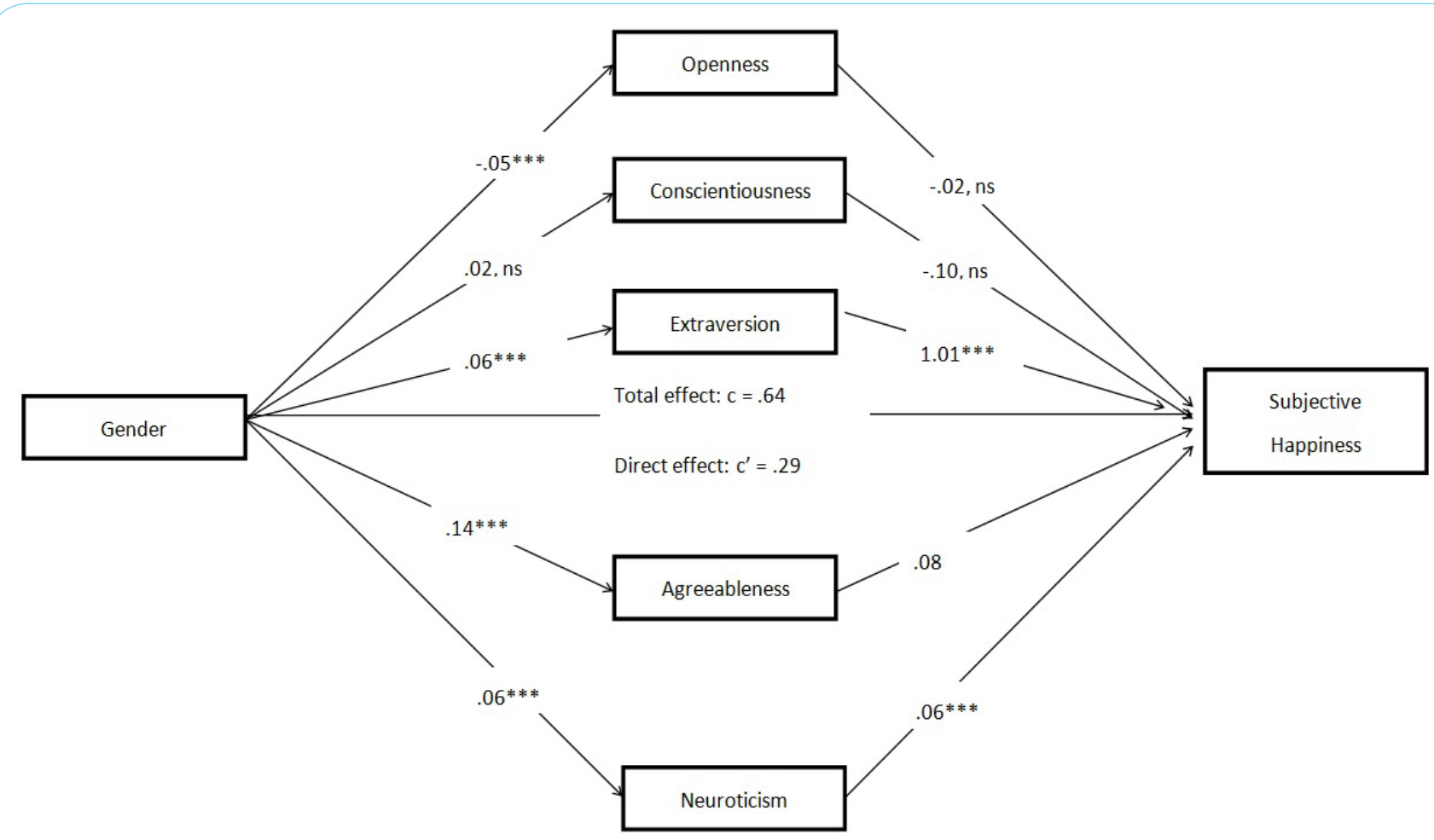

Figure 1: Path model of dispositional factors mediating the relationship between gender and subjective happiness. 


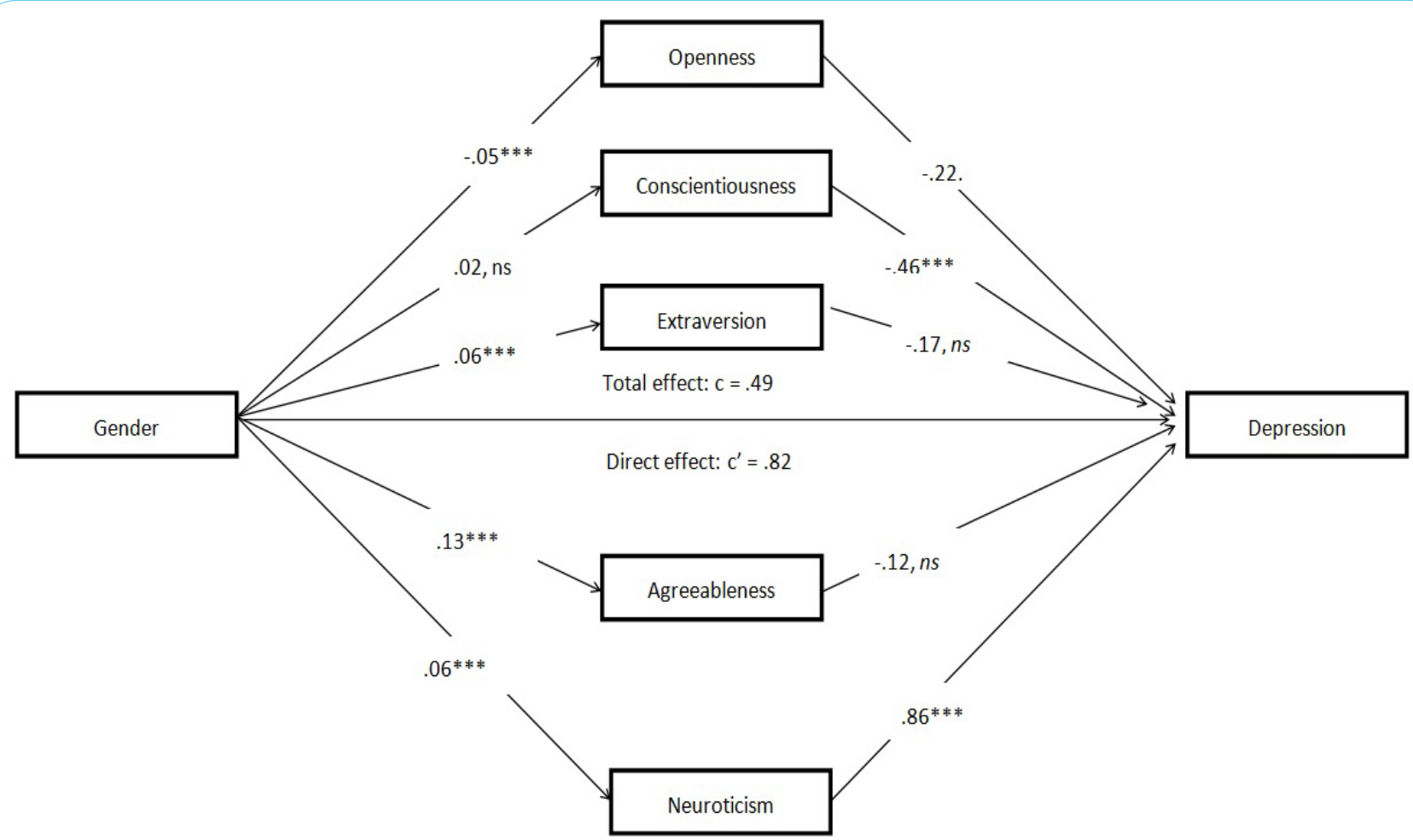

Figure 2: Path model of dispositional factors mediating the relationship between gender and depression.

happiness is achieved in harmonizing conflicts or contradictions with one's surroundings [50]. The Confucian ethics of moderation calls for cultivation of internal harmony of he to achieve interpersonal happiness [51]. This goes to say that for the Chinese, happiness and unhappiness are always present. Secondly, extraversion and neuroticism were found to mediate the gender-happiness link and gender-depression link, respectively. This finding echoed previous studies that women were more emotional than men [11,52], and that extraversion and neuroticism could influence the link between gender and happiness as well as depression [53,54]. After all, extraversion has been a reliable predictor of positive affect, such as happiness [34]. For the Chinese people, it is rare that intense hedonic emotions are expressed even though they are acknowledged as a part of the happiness experience [47] . In the present study, extraversion did account for a significant amount of variance in the relationship between gender and subjective happiness.

Moreover, neuroticism was found to mediate the relationship between gender and depression, which is consistent with previous findings that neuroticism was more predictive of negative affect $[34,54]$. As neuroticism was a strong predictor of depression, it accounted for, in the present study, a significant amount of variance in the relationship between gender and depression as well $[27,55,56]$.

Taken together, these findings show that gender seems to exert the similar pattern of impact on happiness and depression for the Chinese as it did for the Westerners. This came as no surprise as it has been argued that nowadays, neither Hong Kong, Mainland China, nor Taiwan Chinese could claim a pure heritage of Chinese traditions and cultural values due to the increasingly greater impact brought in by Western cultures to Eastern cultures, such as economic globalization, political interactions, strategic alliance, and systemic cultural communications from greater impacts [47,57-61].

\section{Limitations}

This study generated some really intriguing findings in terms of the gender difference on happiness and depression among Chinese undergraduates, with regard to the mediating role of the FFM. However, there are several limitations that need to be addressed in future researches. First of all, even though the present sample size is very big, it includes a homogeneous group, i.e., university students. So it is suggested that future studies ought to consider including samples from different walks of life to verify the present findings. Secondly, the present study used self-report measures; in so doing, participants might fill in the questions in a social desirable way. Therefore, it is recommended that future studies use other ways of data collection to cross-validate the findings. Thirdly, the present study sampled Chinese undergraduates only, future studies ought to recruit students from other countries or societies to justify the cross-cultural validity of the present findings. Last but not the least, future studies ought to examine more variables, such as, to test the directions of the relationship. To conclude this paper, we would like to quote a widely cited quotation from Freud: [The great question that has never been answered, and which I have not yet been able to answer, despite my thirty years of research into the feminine soul, is "What does a woman want?"] (Sigmund Freud: Adapted from The Life and Work of Sigmund Freud by Ernest Jones, 1953). This may be the ultimate answer or question to this study.

\section{Competing Interests}

The authors declare that they have no competing interests

\section{Funding}

This research was funded by a grant from the City University of Hong Kong (Grant No. 7004315). 
Citation: Yue XD, Jiang F, Arjan HN, Jia H, Su-Xia L (2017) How gender matters for happiness: A serial study in of college students in China. Int J Psychol Behav Anal 3: 122. doi: https://doi.org/10.15344/2455-3867/2017/122

Page 5 of 6

\section{References}

1. Argyle M, Martin M, Crossland J (1989) Happiness as a function of personality and social encounters. In J. P. Forgas, \& J. M. Innes (Eds.) Recent advances in social psychology: An international perspective (pp. 189-203). North-Holland: Elsevier.

2. Bassi M, Fave AD (2004) Adolescence and the changing context of optimal experience in time: Italy 1986-2000. Journal of Happiness Studies 5: 155 179.

3. Brickman P, Campbell DT (1971) Hedonic relativism and planning the good society. In M. H. Appley (Ed.), Adaptation-level theory (pp. 287-305). New York: Academic Press.

4. Kaufman G (2000) Do Gender Role Attitudes Matter? Journal of Family Issues 21: 128-144.

5. Perry-Jenkins M, Repetti RL, Crouter AC (2000) Work and Family in the 1990s. Journal of Marriage and Family 62: 981-998.

6. Wood W, Rhades N, Whelan M (1989) Sex differences in positive wellbeing: A consideration of emotional style and marital status. Psychological Bulletin 106: 249-264.

7. Spade JZ, Reese CA (1991) We have come a long way, maybe: College students' plans for work and family. Sex Roles 24: 309.

8. Kaufman G (2005) Gender role attitudes and college students' work and family expectations. Gender Issues. 22: 58-71.

9. Koker S (1991) Comparison of life satisfaction levels of normal adolescents and adolescents with problems, Ankara Üniversitesi, Ankara, unpublished master' thesis.

10. Kelley TM, Stack SA (2000) Thought recognition, locus of control, and adolescent well-being. Adolescence 35: 531-550.

11. Alesina A, Di Tella R, MacCulloch R (2004) Inequality and happiness: are Europeans and Americans different? Journal of Public Economics 88: 2009-2042.

12. Zweig JS (2014) Are women happier than men? Evidence from the Gallup World Poll. Journal of Happiness Studies 16: 515-541.

13. Lu L, Shih JB, Lin YY, Ju LS (1997) Personal and environmental correlates of happiness. Personality and Individual Differences 23: 453-462.

14. Shmotkin D (1990) Subjective well-being as a function of age and gender A multivariate look for differentiated trends. Social Indicators Research 23 : 201-230.

15. Hampton NZ, Marshall A (2000) Culture, gender, self-efficacy and life satisfaction: A comparison between Americans and Chinese people with spinal cord injuries. Journal of Rehabilitation 66: 21-29.

16. Hintikka J (2001) Religious attendance and life satisfaction in the Finnish general population. Journal of Psychology and Theology 29: 158-165.

17. Fugl-Meyer AR, Melin R, Fugl-Meyer KS (2002) Life satisfaction in 18 to 64 year old Swedes: In relation to gender, age, partner and immigrant status. Journal of Rehabilitation Medical 34: 239-246.

18. Katja R, Paivi AK, Marja-Terttu T, Pekka L (2002) Relationships among adolescent subjective well-being, health behavior and school satisfaction. Journal of School Health 72: 243-250.

19. Meliha, H. (2006). Knowledge Management in SMEs. CACCI Journal 1 1-11.

20. Cheng $\mathrm{H}$, Furnham $\mathrm{A}$ (2001) Attributional style and personality as predictors of happiness and mental health. Journal of Happiness Studies 2: 307-327.

21. Mirowsky J, Ross CE (1995) Sex differences in distress: Real or artifact? American Sociological Review 60: 449-468.

22. Fujita F, Diener E, Sandvik E (1991) Gender differences in negative affect and well-being: the case for emotional intensity. J Pers Soc Psychol 61: 427-434.

23. Jiang F, Yue X, Lu S, Yu G, Zhu F, et al. (2016) How Belief in a Just World Benefits Mental Health: The Effects of Optimism and Gratitude. Soc Indic Res 126: 411-423.

24. Lai Y, Zhao J, Yue Y, Wasala NB, Duan D (2014) Partial restoration of cardiac function with I"PDZ nNOS in aged mdx model of Duchenne cardiomyopathy. Hum Mol Genet 23: 3189-3199.

Int J Psychol Behav Anal

ISSN: 2455-3867
25. Scheier MF, Carver CS (1992) Effects of optimism on psychological and physical well-being: Theoretical overview and empirical update. Cogn Ther Res 16: 201-228.

26. Yue XD, Liu KW, Jiang F, Hiranandani NA (2014) Humor styles, selfesteem, and subjective happiness. Psychol Rep 115: 517-525.

27. Costa P Jr, Terracciano A, McCrae RR (2001) Gender differences in personality traits across cultures: robust and surprising findings. J Pers Soc Psychol 81: 322-331.

28. Lu L, Shih JB (1997) Personality and happiness: Is mental health a mediator? Personality and Individual Differences 22: 249-256.

29. Cheng H, Furnham A (2003) Personality, self-esteem, and demographic predictions of happiness and depression. Personality and Individual Differences 34: 921-942.

30. $\mathrm{Lu} \mathrm{L}, \mathrm{Hu} \mathrm{CH}$ (2005) Personality, leisure experiences and happiness. Journal of Happiness studies 6: 325-342.

31. Furnham A, Cheng $H(2000)$ Perceived parental behaviour, self-esteem and happiness. Social psychiatry and psychiatric epidemiology 35: 463470.

32. Eysenck HJ (1983) I do: your guide to a happy marriage. London: Century.

33. Chamorro-Premuzic R, Bennett E, Furnham A (2007) The happy personality: mediating role of trait emotional intelligence. Personality and Individual Differences 8: 1633-1639.

34. DeNeve KM, Cooper H (1998) The happy personality: a meta-analysis of 137 personality traits and subjective well-being. Psychol Bull 124: 197-229.

35. Lyubomirsky S, Lepper H (1999) A measure of subjective happiness: Preliminary reliability and construct validation. Social Indicators Research 46: $137-155$

36. Zung WW (1965) A SELF-RATING DEPRESSION SCALE. Arch Gen Psychiatry 12: 63-70.

37. Gosling SD, Rentfrow PJ, Swann WB (2003) A very brief measure of the Big-Five personality domains. Journal of Research in personality 37: 504528.

38. Preacher KJ, Rucker DD, Hayes AF (2007) Addressing moderated mediation hypotheses: Theory, methods, and prescriptions. Multivariate Behav Res 42: 185- 227.

39. Upmanyu VV, Upmanyu S, Dhingra M (1992) Gender differences in loneliness. Journal of Personality and Clinical Studies 8: 161-166.

40. Koenig LJ, Isaacs AM, Schwartz AJ (1994) Sex differences in adolescents depression and loneliness: why are boys lonelier if girls are more depressed? Journal of Research in Personality 28: 27-43.

41. Wiseman H, Guttfreund DG, Lurie I (1995) Gender differences in loneliness and depression of university students seeking counselling. British Journal of Guidance and Counselling 23: 231-243.

42. Brody LR (1997) Gender and emotion: Beyond stereotypes. Journal of Social Issues 53: 369-394.

43. Levant RF, Kopecky G (1995) Masculinity reconstructed: Changing the rules of manhood- at work, in relationships, and in family life. New York, NY: Plume Publishing.

44. Brody LR (1999) Gender, emotion, and the family. Cambridge: Harvard University Press.

45. Becker JA, Smenner PC (1986) The spontaneous use of thank you by preschoolers as a function of sex, socioeconomic status and listener status. Language in Society 15: 537-546.

46. Gordon AK, Musher-Eizenman DR, Holub SC, Dalrymple J (2004) What are children thankful for? An archival analysis of gratitude before and after the attacks of September 11. Journal of Applied Developmental Psychology 25: 541-533.

47. Lu L (2001) Understanding happiness: A look into the Chinese folk psychology. Journal of Happiness Studies 2: 407-432.

48. Bruner J (1990) Acts of meaning. Cambridge, MA: Harvard University Press.

49. Luo L, Gilmour R, Kao SF (2001) Cultural values and happiness: an EastWest dialogue. J Soc Psychol 141: 477-493. 
Citation: Yue XD, Jiang F, Arjan HN, Jia H, Su-Xia L (2017) How gender matters for happiness: A serial study in of college students in China. Int J Psychol Behav Anal 3: 122. doi: https://doi.org/10.15344/2455-3867/2017/122

Page 6 of 6

50. Lu L, Gilmour R (2004) Culture and conceptions of happiness: Individual oriented and social oriented SWB. Journal of Happiness Studies 5: 269291.

51. Yue XD (1994) An ethnographic study of stress coping behaviours among Chinese college students in Beijing. Educational Research Journal 9: 6576.

52. Cenkseven F (2004) Üniversite öğrencilerinde öznel ve psikolojik iyi olmanın yordayıcılarının incelenmesi. Yayımlanmamış doktora tezi, Çukurova Üniversitesi Sosyal Bilimler Enstitüsü, Adana.

53. Hills P, Argyle M (2001) Happiness, introversion-extraversion and happy introverts. Personality and individual Differences 30: 595-608.

54. Davila J, Karney BR, Hall TW, Bradbury TN (2003) Depressive symptoms and marital satisfaction: within-subject associations and the moderating effects of gender and neuroticism. J Fam Psychol 17: 557-570.

55. Lynn R, Martin T (1997) Gender differences in extraversion, neuroticism, and psychoticism in 37 nations. J Soc Psychol 137: 369-373.

56. Goodwin RD, Gotlib IH (2004) Gender differences in depression: the role of personality factors. Psychiatry Res 126: 135-142.

57. Hwang KK (1987) Face and power: the Chinese power game. American Journal of Sociology 92: 944-974.

58. Bond MH (1996) Handbook of Chinese psychology. New York: Oxford Univer. Press.

59. Yue XD, Wong AY, Hiranandani NA (2014) Humor styles and loneliness: a study among Hong Kong and Hangzhou undergraduates. Psychol Rep 115: $65-74$

60. Jones E (1953) The Life and Work of Sigmund Freud First Edition. New York: Basic Books.

61. Wu PY, Wu PY (1990) The Confucian's Progress: Autobiographical Writings in Traditional China (p. 283). Princeton, NJ: Princeton University Press. 